\title{
Okavango Basin -
}

\section{Relative Importance of Ecosystem Services (ESS) among Stakeholders}

Ecosystem services are those contributions of the natural world which people value (adapted from Bateman et al. 2011). In other words, ESS are the "flow of services (outcomes of structure and processes) provided by ecological assets in some assessment period" (Bateman et al. 2011). While provided by Nature, ecosystem services are necessary and appreciated by people. Thus, ESS bring together issues of the environment and development, enabling decision-makers to view the two as interrelated.

TFO selected 11 important ESS for its analysis. A 12th service (Fish) was added after a first round of pre-test interviews revealed its importance as an ESS in the Okavango River Basin (ORB). Thus, this analysis considers 12 important ESS provided by the Okavango River Basin ecosystem. Different people in the basin may have different perceptions about how important ESS are to them, depending on several factors such as the scale at which they interact with nature and their sector of activity. Perceptions and priorities for given ecosystem services may also vary depending on the local geographical characteristics of the basin. Thus, different perceptions exist among stakeholders of the different countries of the ORB.

In the course of 90 interviews conducted from November 2012 to June 2013, 75 stakeholders of Angola, Namibia and Botswana who are active at the local, district/regional/provincial, national or basin scale in each country, ranked the 12 ESS from 1 to 12 by order of importance or priority from their own perception (1: highest and 12: lowest importance). Details on the methodology used are available in the Electronic Appendix.

\section{General Ranking}

Confirming its key position in the ecosystem, the ESS River water supply/availability was ranked first (Fig.1) by each country and at each scale (Tab.1).
Stakeholders highlighted the fact that human livelihoods, most economic activities and the ecosystem itself all rely on water as their basis.

At second position, but with a high level of disagreement, come ex aequo the system-related or more holistic ESS such as Wild species diversity, Climate regulation and Hazard regulation (mean ranking of 5). Their position in the ranking of the different stakeholders varies greatly from top to very low importance. When seen of high importance, stakeholders assumed that the delivery of these ESS is a precondition to all other services, just as Water availability is.

Of middle importance comes the ESS Environmental settings (median rank 6), although, in this case also, its meaning for each stakeholder and its position in the ranking varied strongly in the sample. Also with a median rank 6 , but with a higher level of agreement, come Trees and then Staple crops and Wildlife. The ESS Trees was scored by stakeholders for their

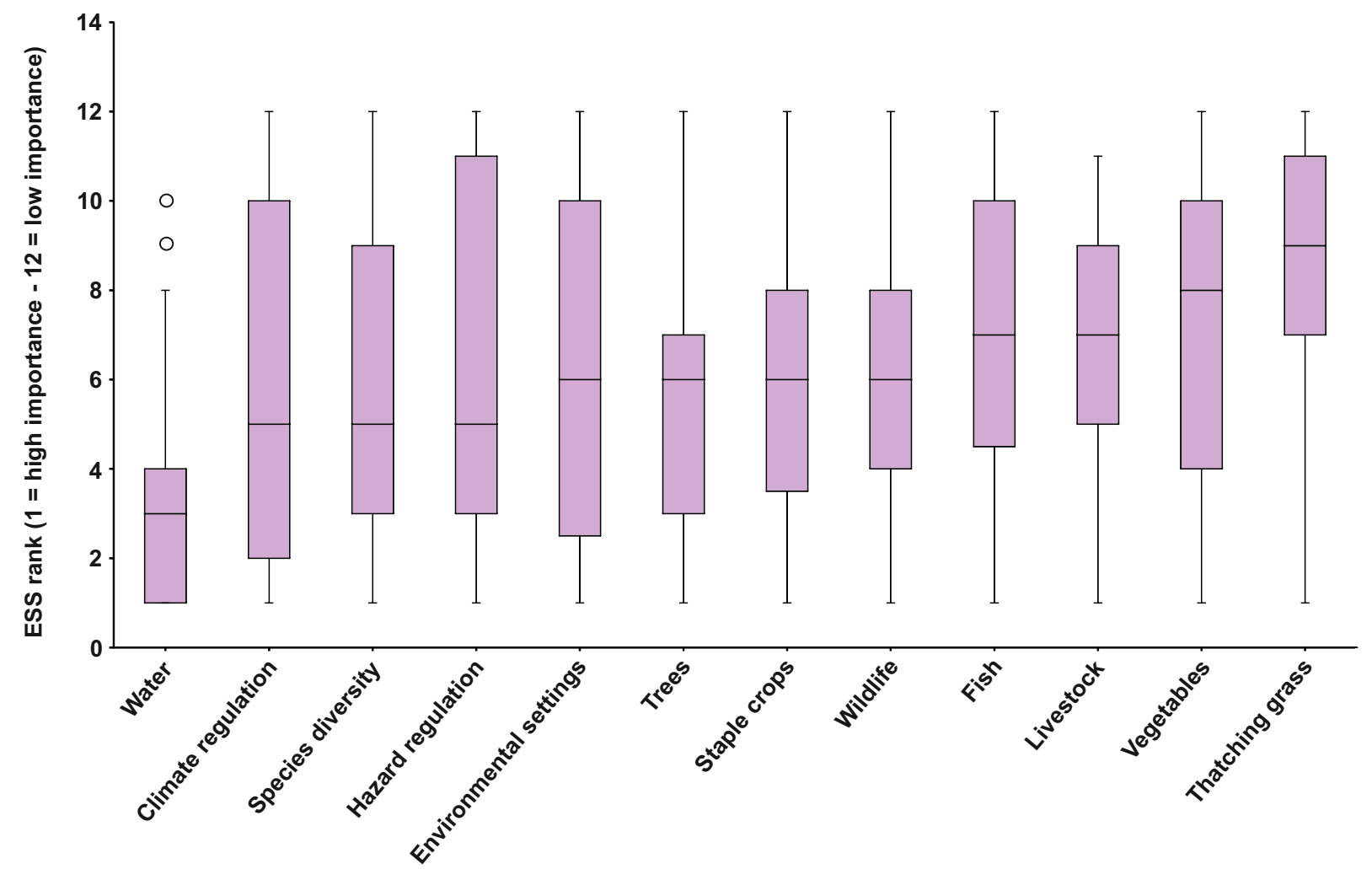

Fig. 1: Boxplots representing the distribution of ranking among all respondents in the $O R B(N=75)$. 


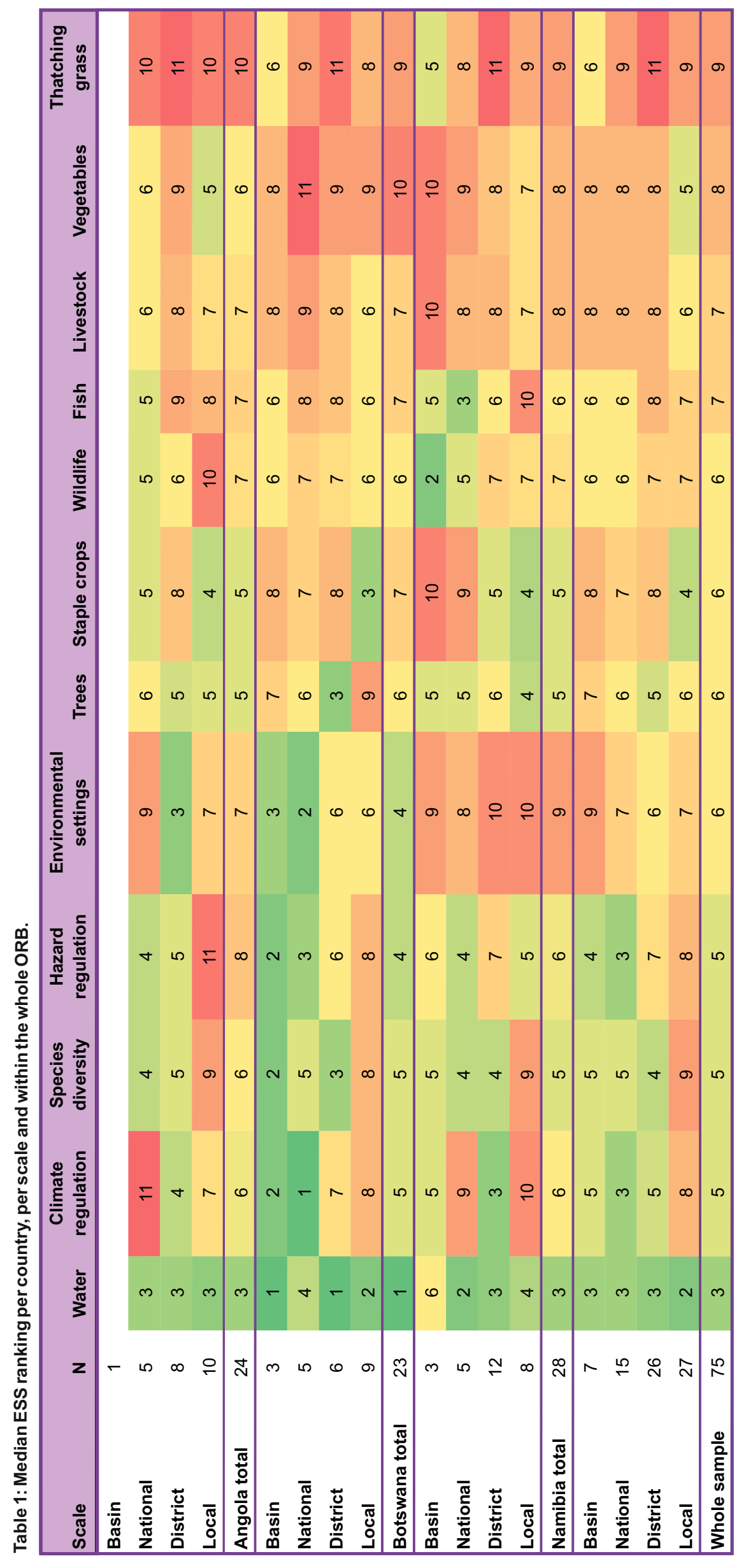


function of ecosystem engineer and stabilizer, while Staple crops are the basis of the local population's livelihoods. Wildlife is seen as an asset and inherent part of the system, but dependent on more highly ranked ESS.

Of rather low importance are the ESS
Fish and Livestock, which is surprising given the current increase in fishing communicated by stakeholders and the current developments in livestock production at the smallholder and ranching scale in Angola and Namibia. Finally, on average among all stakeholders of the
ORB, Thatching grass and Vegetables are perceived as the least important ESS. Although they surely contribute to the wellbeing of the local population, they are not perceived as essential for them nor the ORB as a system. The low level of agreement concerning ESS Vegetables may be related

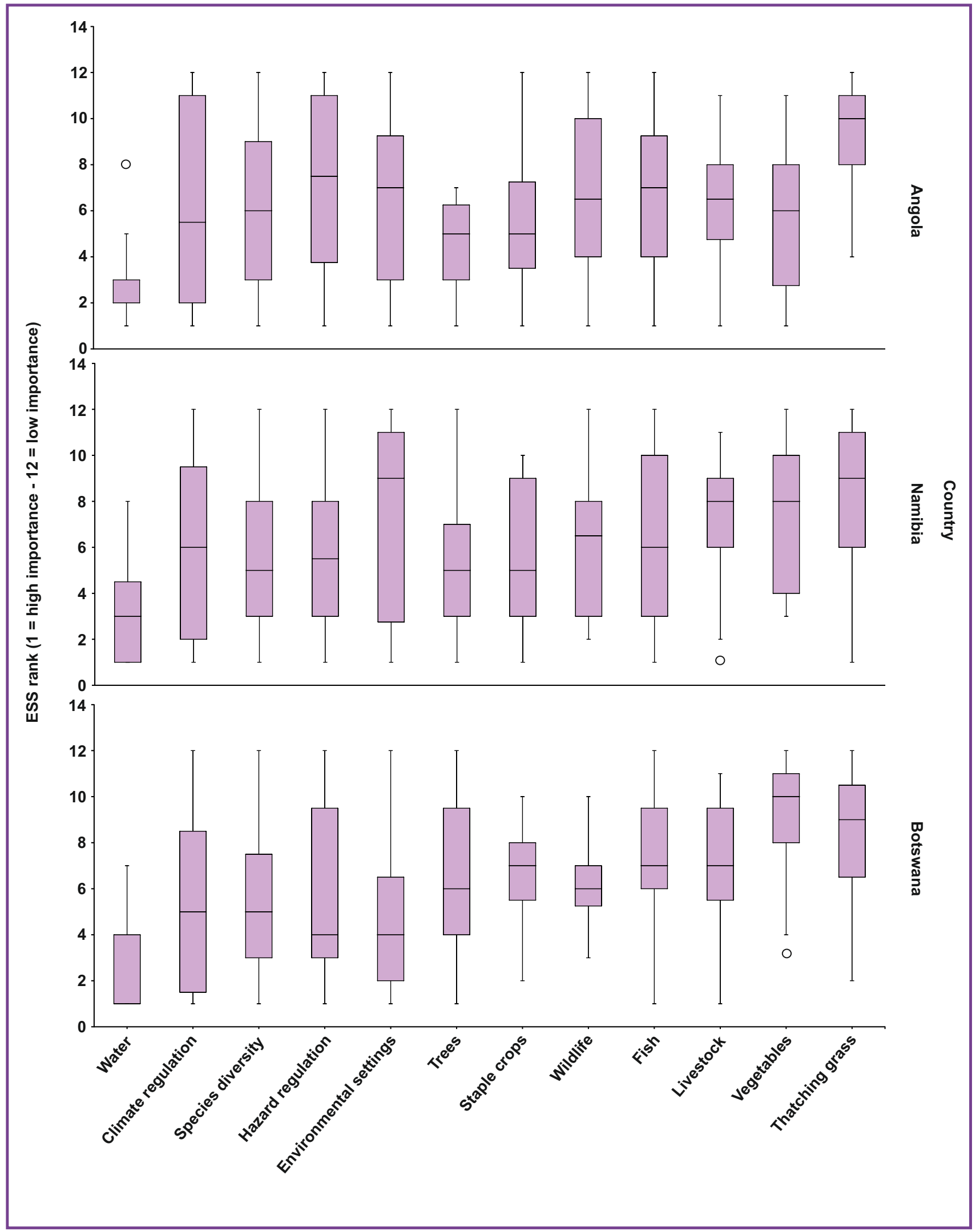

Fig. 2: Boxplots comparing the distribution of ESS ranking among respondents of the three countries Angola, Namibia and Botswana. 


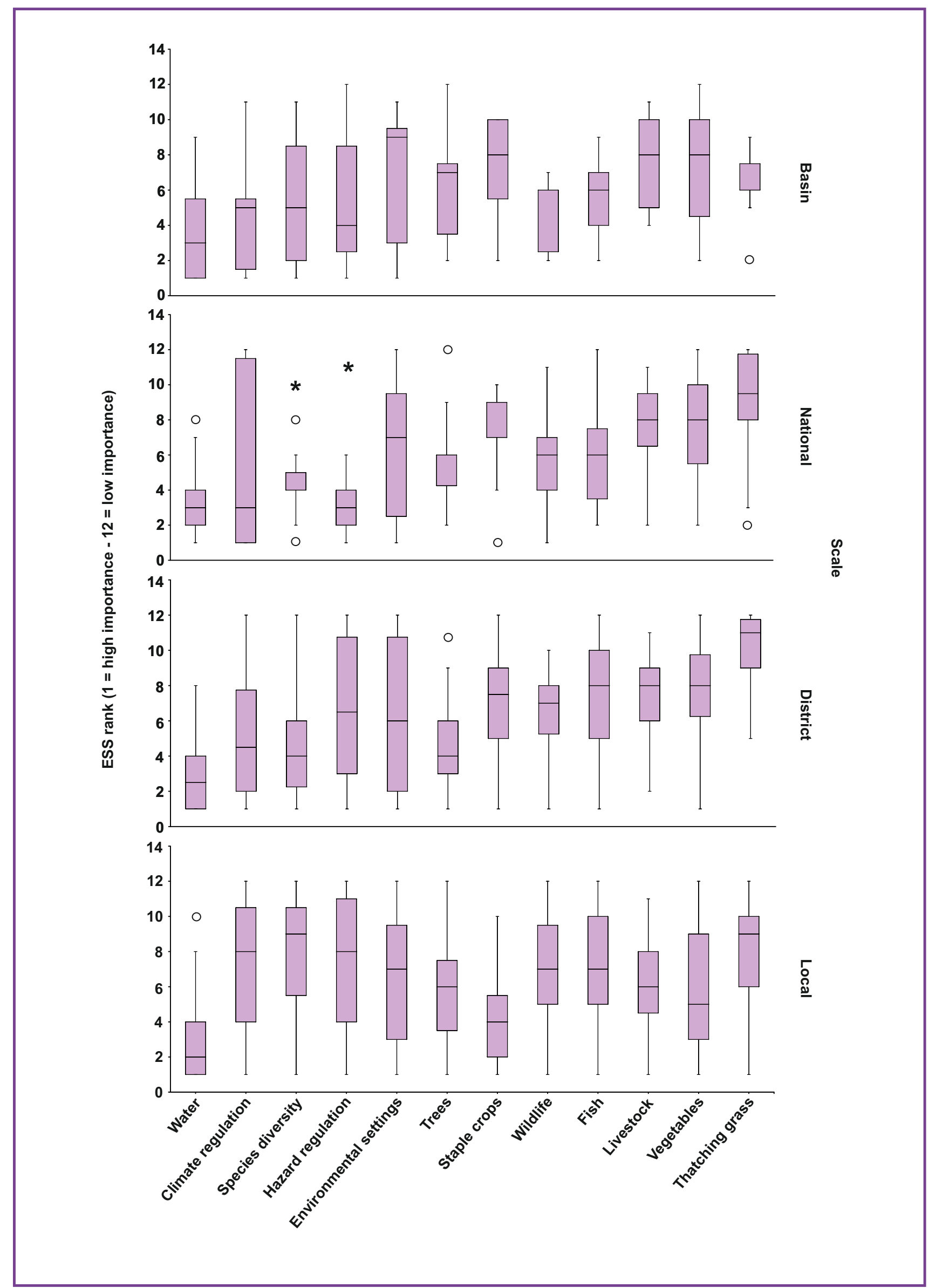

Fig. 3: Boxplots comparing the distribution of ESS ranking among respondents at four different scales: basin, national, mesoscale (district, region, province) and local. 
to the fact that the different areas of the ORB are more or less suitable for significant vegetable production.

\section{Country profiles (Fig. 2)}

At the country level, Botswana stands out with a high valuation of ESS regulating the system such as Environmental settings and Wild species diversity, although with some disagreement among stakeholders. Climate regulation and Hazard regulation have even greater differences in their importance for the various stakeholders. The high ranking of Wild species diversity and Environmental settings can be linked first to the fact that stakeholders of the Botswana part of the ORB have often been involved in planning and decision-making on land use in the Okavango Delta, and are aware of the uniqueness of the Delta as a pristine ecological system which they want to conserve. This conservation choice is strengthened by the political decision of developing tourism, which provides an important value-addition to these ESS. In addition, climate patterns and floods, as an important hazard, shape the current natural system and restrict opportunities for rural livelihoods in the region, which strongly depend on the environment. Interestingly, despite its traditional importance, the ESS Livestock is not perceived as more important for the Batswana part of the ORB by stakeholders in Botswana than elsewhere in the basin.

Angola stands out as having a strong focus on agricultural production (Staple crops, Vegetables and Livestock have respectively the same or a higher rank than in Namibia and Botswana). Wild species diversity and Environmental settings are also highly ranked in relation to the contribution of natural resources to livelihoods and to forthcoming tourism opportunities (KAZA transboundary project); yet they are the object of very strong differences of opinion among Angolan stakeholders. This trend, however, may reflect the current land use and the plans and priorities for land use of Angola, where agricultural production is increasingly important for the state and local economy and livelihoods. On the other hand, Hazard regulation and Wildlife are ranked particularly low among local respondents in Angola as compared to the two other countries.

Namibia occupies an intermediate position between the two foci of its neighboring countries. While Namibian stakeholders give strong priority to the Staple crops, the ESS Vegetables and Livestock have a medium to low importance. Following staple food production, the system-related services Hazard regulation, Climate regulation and Wild species diversity constitute the next most important group of ESS. Fish is perceived as slightly more important than in the two other countries, indicating its increasing role in the diet of the population - next to a staple crop production, which is not very diverse - for subsistence as well as commercial purposes. Finally, compared to the other two countries, the ESS Environmental settings also has a particularly low importance in Namibia, albeit with a wide range in its ranking here. This might be related to the fact that until now the Namibian area of the ORB has been more intensively used and degradation-prone than the share of the basin located in the two other countries.

\section{Scales specificities (Fig. 3)}

Not surprisingly, the local scale is strongly distinct from the general ranking and the other scales, firstly by its focus on the provisioning services: ESS Staple crops, Vegetables and Livestock are ranked from $2^{\text {nd }}$ to $4^{\text {th }}$. In line with its cultural importance, Livestock was slightly more important at the local scale in Botswana than in the two other countries. Secondly, system-related ESS such as Climate regulation, Hazard regulation and Species diversity were ranked particularly low. At the Angolan local scale, Wildlife is perceived as particularly not important.

Respondents attribute a low importance at the basin scale to ESS Environmental settings and Staple crops compared to the other scales. In contrast, they highlight the importance of ESS Thatching grass (also at the national scale in Namibia) based on its perceived double function of ecosystem engineer for the water system of the Okavango River and on its cash value for the riparian population.

At the national level Hazard regulation and Climate regulation are given more importance compared to the general ranking (although less so when looking at Namibia and Angola individually). This may be related to the fact that the national scale is where policies and solutions must be found for the continuous provision of these services or for solutions to deal with changes in their provision.

Finally, at the meso-scale (district, provincial, regional), particularly importance is attributed to the ESS Wild species diversity and Trees.

\section{Disagreement and agreement at the country and scale levels}

Differences in ranking among scales within countries are greater than differences among countries. In particular, rankings from stakeholders within the local scale across countries are very similar, and the same applies to rankings among stakeholders of the provincial/ district/regional scale. It is mainly governance priorities at the basin and national scales which differ among the three countries of the ORB. Importantly, Climate regulation, Wildlife and Wild species diversity are perceived as important ESS among all stakeholders, but are not found in the top three priorities of any national ranking.

\section{Conclusion}

The fact that most stakeholders view River water availability as the basis of all things shows the possible conflicts which may arise around water, depending on which aspects of well-being and which other ESS stakeholders feel water should be used for. The results show that Botswana is most distinct at nearly all scales in its perception of the human-environment relationships, while Namibia and Angola have more similar priorities, especially at the national scale. One can presume that the uniqueness of the Okavango Delta gives this part of the Okavango River an additional status than being merely the water provider, a perception which prevails in the two other countries. Whilst the similarity between Angola and Namibia may be an indicator of shared interest, it may also indicate a risk of competition for the limited resource water. The results further suggest that a common target for the ORB should be securing the sustainability of provisioning ESS for riverine populations at the local scale. Differences in priorities at national scales may either lead to conflicts or to cooperation, depending on the relative perceived advantages of the different ESS within the basin. The strong agreement at the regional/provincial/district scale 
suggests that this scale may be an asset to consider in building cooperation among countries.

\section{Acknowledgements}

This study was funded by the BMBF (The Future Okavango project). For details see authors' general acknowledgements in this volume.

\section{Reference}

Bateman, I., Mace, G.M., Fezzi, C., Atkinson, G., Turner K. (2011): Economic Analysis for Ecosystem Assessments. Environmental Research Economics. 48:177-218. CrossRef

Responsible authors: S.E. Domptail, O. Mundy 